[Received/Recebido: Dezembro 5, 2019]

[Accepted/Aceito: Fevereiro 18, 2020]

[Última atualização: Junho 27, 2020]

vol. 02, $n^{\circ} .23$, Curitiba, 2019. pp. $373-389$

Nota de Esclarecimento de Publicação (ANEXO I)

\title{
O EXERCÍCIO DA ADVOCACIA E O CRIME DE LAVAGEM DE DINHEIRO: POSSIBILIDADE OU NÃO DE RESPONSABILIZAÇÃO DOS ADVOGADOS PELO RECEBIMENTO DE HONORÁRIOS ADVOCATÍCIOS MACULADOS POR CAPITAL ILÍCITO
}

BEATHRYS RICCI EMERICH ${ }^{1}$
SÉRGIO FERNANDO MORO

\begin{abstract}
Aproveito a oportunidade para iniciar este trabalho retratando-me, juntamente com o meu orientador, Dr. Sérgio Moro, pelo erro metodológico que cometi, ao omitir inadvertidamente no presente estudo as referências à citação de um parágrafo do artigo científico de autoria do ilustre jurista, Dr. Marcelo Augusto Rodrigues de Lemos. A mencionada citação está devidamente corrigida metodologicamente, mediante a inclusão da referência em nota de rodapé. Além de pedir desculpas ao nobre jurista pelo ocorrido, declaro que as suas ideias sobre o presente tema inspiraram-me na elaboração deste artigo científico (Vide Anexo I).
\end{abstract}

Beathrys Ricci Emerich

\section{RESUMO:}

O presente trabalho tem o objetivo abordar os delitos da lavagem de dinheiro e de corrupção, bem como sua incidência tanto em âmbito nacional quanto internacional. $\mathrm{O}$ tema proposto neste estudo "O exercício da advocacia e o crime de lavagem de dinheiro: responsabilização dos advogados pelo recebimento de honorários advocatícios maculados por capital ilícito", tem o objetivo de refletir sobre a criminalidade econômica na qual está inserida. $\mathrm{O}$ delito em comento tem-se tornado cada vez mais habitual e recebido enfoque especial da mídia, talvez pelo envolvimento de políticos e empresários renomados em escândalos recentes que tiveram como pano de fundo,

\footnotetext{
${ }^{1}$ Graduada em Direito pela Pontifícia Universidade Católica do Paraná (2017). Pós-graduada em Direito Aplicado pela Escola da Magistratura do Paraná (2018). Atualmente é advogada e mestranda em Direito Empresarial e Cidadania pelo Centro Universitário Curitiba (Unicuritiba).

2 Orientador. Ministro da Justiça e da Segurança Pública do Brasil entre 01/2019 e 04/2020. Foi Juiz Federal da 13. ${ }^{a}$ Vara Criminal Federal de Curitiba/PR, especializada em crimes financeiros, de lavagem de dinheiro e praticados por grupos criminosos organizados. Trabalhou como Juiz instrutor no Supremo Tribunal Federal durante o ano de 2012. O autor cursou o Program of Instruction for Lawyers na Harvard Law School em julho de 1998 e possui título de mestre e doutor em Direito do Estado pela Universidade Federal do Paraná - UFPR. Escreveu livros e artigos especializados na área jurídica. Participou do International Visitors Program organizado em 2007 pelo Departamento de Estado norte-americano com visitas a agências e instituições dos EUA encarregadas da prevenção e do combate à lavagem de dinheiro. Lecionou entre 2007 a 2016 como Professor Adjunto de Direito Processual Penal da Universidade Federal do Paraná - UFPR. É Professor contratado da graduação e pós-graduação do Unicuritiba - Centro Universitário Curitiba. Recebeu o título de Doctor of Laws, honoris causa, pela University of Notre Dame du Lac, South Bend, Indiana, em 2018.
} 
entre outros crimes, o de lavagem de dinheiro. Sendo assim, uma questão ainda soa muito instigante: "o advogado pode ou não pode ser compelido a trazer ao conhecimento fato que acobertado pelo sigilo profissional sequer na condição de testemunha?". E, ainda, "o advogado pode ou não pode ser responsabilizado pela obtenção de remuneração advocatícia maculada oriundos de capital ilícito?" As razões que tornam importantes a realização da pesquisa proposta é o entendimento de quais circunstâncias pode-se haver a responsabilização dos advogados pelo obtenção de remuneração advocatícia maculada por capital ilícito e o delito em discussão? A metodologia a ser adotada será a dedutiva, isto é, análises de doutrinas, artigos e legislações. Não será empregado o método indutivo devido à ausência de jurisprudências acerca do tema até o presente momento. O objetivo geral pretende esclarecer a eventualidade de responsabilização dos advogados pela obtenção de remuneração advocatícia maculada por capital ilícito. E as metas específicas pretendem buscar um levantamento histórico acerca do delito em comento, conceituar o delito de lavagem de dinheiro, explicar as etapas para a efetivação do crime de lavagem de dinheiro, apontar as finalidades do delito da lavagem de capitais, esclarecer o que prevê o Estatuto da Advocacia, apontar o que dispõe a Lei Antilavagem e, por fim, identificar a factibilidade de responsabilização dos advogados pelo recebimento de honorários advocatícios maculados. A defesa das prerrogativas do profissional é consequência do resguardo mais primordial das garantias individuais previstas em nosso texto constitucional.

Palavras-chave: lavagem de dinheiro; honorários advocatícios maculados; sigilo do advogado; advocacia criminal.

\begin{abstract}
:
This study is aimed at addressing the crime of money laundering and the possibility of a lawyer's liability for having received dirty funds in the course of his or her representation. The theme proposed in this study, "The Practice of Law and the Crime of Money Laundering: Liability of Lawyers for Receiving Attorney Fees tainted by Illicit funds", aims to consider economic crimes that incorporate money laundering. This particular crime has become increasingly widespread and received attention from the media, perhaps because of the involvement of well-known politicians and businessmen in recent scandals against the backdrop of money laundering, among other crimes. Thus, some questions still sound very intriguing: "Should lawyers be compelled to bring to light a fact protected by confidentiality, even as a witness? What should be said about a resolution in which a lawyer becomes an informant about the clients?" And, also: "Can an attorney be held responsible for having received fees which were tainted by illicit money?" The reason why this research becomes important is the relevance of understanding the circumstances under which lawyers may be held responsible for receiving attorney fees tainted by illicit fund and by the crime of money laundering. The methodology used in this study is deductive, that is, the analysis of legal doctrines, articles and legislation. The inductive method will not be used due to the absence of jurisprudence on the subject until now. The general aim is to clarify the possibility of liability of lawyers for receiving attorney fees obtainted by illicit money. The specific objectives are: to survey the historical context underlying the crime of money laundering; to conceptualize this crime; to explain its stages; to point out its purposes; to clarify what is provided by the Statute Governing the Practice of Law and the Anti-Money-Laundry Law; and finally, to identify the possibility of liability of lawyers for receiving tainted fees. The defense of a professional's prerogatives is an implication of the most fundamental safeguards of individual guarantees provided for in our constitutional text.
\end{abstract}

Keywords: money laundering; tainted fee; attorney-client confidentiality; criminal advocacy.

\title{
1 INTRODUÇÃO
}

O presente trabalho tem o objetivo abordar as situações em que poderá haver a responsabilização dos advogados pela obtenção de remuneração advocatícia maculada por capital ilícito e o crime em comento, esclarecendo, assim, se seria possível o advogado ser um lavador de dinheiro.

Rev. Relações Internacionais do Mundo Atual, Curitiba v.2 n.23, p.373-389, Abril-Junho. 2019. 
Por essa razão e por facilitar o entendimento acerca do tema, primeiramente, será analisada a origem histórica do delito da Lavagem de Dinheiro, que se deu nos Estados Unidos e na Itália. A partir desta análise, chega-se ao conceito do delito, que apesar de não ser unívoco na doutrina, converge sempre para um mesmo sentido.

$\mathrm{Na}$ sequência, serão analisados os modelos de fases do delito elaborado pelo FAFT/GAFI, composto por três fases: colocação, ocultação e integração desse dinheiro no sistema econômico. Tais fatores são relevantes para o estudo e o entendimento da criminalização e do prevenção da lavagem de dinheiro.

$\mathrm{Na}$ segunda parte do trabalho será estudado a contextualização dos honorários advocatícios. Para alcançar esse objetivo, inicialmente será abordada a responsabilização dos advogados perante o Estatuto da Advocacia e a Ordem dos Advogados do Brasil (OAB) - Lei n. 8.906, de 4 de julho de 1994, que dispõe sobre as atividades privativas da advocacia.

Nesse item, busca-se estudar o que dispõem as leis antilavagem e o Estatuto da Advocacia, bem como a concepção sobre a factibilidade de ocorrência da consumação para a responsabilização de obtenção de remunerção advocatícia oriunda de capital ilícito.

Assim sendo, se o advogado não pode ser compelido a trazer ao conhecimento fato que acobertado pelo sigilo profissional sequer na condição de testemunha, o que dizer de uma norma que pretende tornar o advogado o delator de seu cliente?

Feitas essas ponderações introdutórias, pode-se constatar a complexidade e a relevância da questão objetivada neste trabalho, que não tem o desígnio de esgotar o assunto, mas apenas, de trazer alguns apontamentos iniciais e importantes acerca da possibilidade de responsabilização dos advogados pela obtenção de remuneração advocatícia maculadas pela lavagem de dinheiro e valores ilegais.

\section{LAVAGEM DE DINHEIRO}

\subsection{EVOLUÇÃO HISTÓRICA E CONCEITUAÇÃO}

Os Estados Unidos da América foi o primeiro a criminalizar o delito da lavagem de capitais, no início do século XX e, a Itália, em 1978, nos chamados "anos de chumbo"3.

\footnotetext{
${ }^{3}$ CERVINI, Raúl; TERRA DE OLIVEIRA, William; GOMES, Luiz Flávio. Lei de Lavagem de Capitais. São Paulo: Revista dos Tribunais, 1998, p. 18
}

Rev. Relações Internacionais do Mundo Atual, Curitiba v.2 n.23, p.373-389, Abril-Junho. 2019. 
A Operação denominada "Mani pulite", ocorrida na Itália, foi uma investigação judicial que redesenhou o quadro político do país. Essa operação teve início em fevereiro de 1992, na cidade de Milão, com a prisão do diretor de uma sociedade sem fins lucrativos, Mario Chiesa, que portava propina no bolso ${ }^{4}$.

Assim como na Itália, nos Estados Unidos, em 1993, o franco crescimento da exploração dos jogos e das drogas, o utilização de lavanderias ou limpeza de automóveis negócios baseados no uso de valores em espécie - já não era suficiente para circular o dinheiro ilícito ganho. Dessa forma, alguns mafiosos americanos, perceberam que a forma mais ágil de ocultar ativos ilegais seria colocando o dinheiro em uma jurisdição que não cooperasse com os Estados Unidos para o retensão e restituição, o que deu origem à invenção dos offshore (os famosos paraísos fiscais, cujo centro financeiro possui menor tributação e maior regulamentação financeira) $)^{5}$.

No Brasil, a lavagem de capitais não surgiu do acaso. É um costume utilizado por criminosos quanto ao emprego dos mais variados mecanismos para dar aparência lícita ao patrimônio constituído de bens e de capitais obtidos mediante ação delituosa ${ }^{6}$.

A criação do crime de lavagem de capitais nasce da urgência de se combater grupos mafiosos, o comércio ilegal de bebidas, a exploração do jogo, mas o principal motivo foi o prevenção ao tráfico internacional de drogas ${ }^{7}$.

Barros assevera ainda:

“[...] quando foi celebrada a Convenção de Viena, subscrita em 19 de dezembro de 1988, por representantes de mais de 100 países, durante a Conferência das Nações Unidas, já havia amadurecido o consenso de que a criminalização da lavagem de dinheiro deveria constar dos ordenamentos jurídicos internos dos países presentes aquele ato. Essa foi à reação eleita para se enfrentar a criminalidade violenta e altamente lucrativa, como o tráfico de drogas e crime organizado, que se utilizava do sistema financeiro internacional" 8 .

\footnotetext{
${ }^{4}$ BARBACETTO, Gianni; TRAVAGLIO, Peter Gomez Marco. Operação Mãos Limpas - A verdade sobre a operação italiano que inspirou a Lava Jato. Porto Alegre: CDG, 2016, p. 875.

${ }^{5}$ PINTO, Edson. Lavagem de Capitais e Paraísos Fiscais. São Paulo: Atlas, 2007, p. 50.

${ }^{6}$ BARROS, Marco Antônio de. Lavagem de Capitais e Obrigações Civis Correlatas: com comentários, artigo por artigo, à Lei 9.613/1998. 4. Ed. São Paulo: Editora Revista dos Tribunais, 2013, p. 33.

${ }^{7}$ PRADO, Luiz Regis. Curso de Direito Penal Brasileiro. 11. ed., São Paulo: Revista dos Tribunais, 2012, p. 363.

${ }^{8}$ BARROS, Marco Antônio de. Lavagem de Capitais e Obrigações Civis Correlatas: com comentários, artigo por artigo, à Lei 9.613/1998. 4. Ed. São Paulo: Editora Revista dos Tribunais, 2013, p. 35.
}

Rev. Relações Internacionais do Mundo Atual, Curitiba v.2 n.23, p.373-389, Abril-Junho. 2019. 
Iniciando-se através da análise da origem e da evolução histórica do delito em comento, forma-se o conceito e finalidades de tal delito.

A legislação brasileira - Lei n. 12.683/2012, que alterou a antiga Lei n. 9.613/1998, tipifica o delito da lavagem de dinheiro em seu artigo $1^{\circ}$ :

“Art. $1^{\text {o }}$ Ocultar ou dissimular a natureza, origem, localização, disposição, movimentação ou propriedade de bens, direitos ou valores provenientes, direta ou indiretamente, de infração penal"9.

Assim, na visão de Vera Lucia Feil Ponciano, lavagem de dinheiro:

“[...] é o processo pelo qual o criminoso transforma recursos ganhos em atividades ilegais em ativos com uma origem aparentemente legal. Essa prática geralmente envolve múltiplas transações, usadas para ocultar a origem dos ativos financeiros e permitir que eles sejam utilizados sem comprometer os criminosos. A dissimulação é, portanto, a base para toda operação de lavagem que envolva dinheiro proveniente de um crime antecedente ${ }^{10}$.

Segundo a definição dada pelo Banco do Brasil, a lavagem de capitais é "o processo pelo qual os criminosos transformam o valor auferido ilicitamente (dinheiro 'sujo') em dinheiro aparentemente lícito (dinheiro 'limpo'), de maneira a 'reciclar' o dinheiro sujo para que ele aparente ter sido obtido de fonte lícitas"11.

Em complemento a essa definição, a Receita Federal do Brasil conceituou que: "a expressão "lavar dinheiro" se refere a uma ação passada ilegal que produziu valores, bens e direitos que, sem um tratamento apropriado, deixam seus autores ou beneficiários com altos riscos frente a uma ação judicial"12.

\footnotetext{
${ }^{9}$ BRASIL. Lei no 12.683, de 9 de julho de 2012. Disponível em: http://www.planalto.gov.br/ccivil_03/_Ato20112014/2012/Lei/L12683.htm. Acesso em: 10 nov. 2019.

10 PONCIANO, Vera Lúcia Feil. Justiça Federal - Organização, competência, administração e funcionamento. Curitiba: Juruá, 2008, p. 156.

11 BANCO do Brasil. O que é e como ocorre a lavagem de dinheiro e o financiamento ao terrorismo. Disponível http://www.bb.com.br/portalbb/page251,105,5269,0,0,1,1.bb?codigoNoticia=2970\&codigoMenu=580. Acesso em: 13 nov. 2019.

12 ROSA, Rodrigo Silveira. Delito de omissão - Sonegação fiscal não consiste em infração antecedente da lavagem. Disponível em: http://www.conjur.com.br/2014-nov-30/sonegacao-fiscal-nao-consiste-infracaoantecedente-lavagem. Acesso em: 21 nov. 2019.
}

Rev. Relações Internacionais do Mundo Atual, Curitiba v.2 n.23, p.373-389, Abril-Junho. 2019. 
Neste viés, a consumação do referido crime apenas ocorrerá anteriormente à existência de uma conduta criminosa ${ }^{13}$. E, sendo assim, Sérgio Fernando Moro, ao comentar sobre o assunto, destaca que "o objetivo é isolar economicamente a atividade criminal"14.

\title{
2.2 ETAPAS E FINALIDADE DA LAVAGEM DE CAPITAIS
}

Dos vários modelos de fases existentes, resumidamente, o processo deste delito segue três etapas independentes elaborados pelo GAFI/FAFT - Grupo de Ação Financeira contra a Lavagem de Dinheiro e o Financiamento do Terrorismo, que, não raro, se dão simultaneamente. São elas: colocação, ocultação e integração.

A primeira fase, colocação ou Placement:

\begin{abstract}
"consiste no ingresso dos recursos ilícitos no sistema econômico. Para isso, são realizadas operações como, por exemplo, depósitos em contas correntes bancárias; pagamento de boletos bancários e convênios; compra de produtos e serviços financeiros; aplicações em depósitos a prazo, poupança, fundos de investimento; compra de bens" $" 15$.
\end{abstract}

Nessa etapa, explica Sérgio Fernando Moro que: “o produto do crime é desvinculado de sua origem material"16. Para que isso ocorra, temos que uma das formas mais comum de se fazer concretizar essa primeira etapa da lavagem é o envio do dinheiro ao exterior, que pode ocorrer através de doleiros, ou por meio de uma agência localizada em região de fronteira, as chamadas "off-shore".

Em seguida, ocorre a segunda etapa, ocultação, dissimulação, circulação ou layering:

"Em que são realizadas diversas operações com o objetivo de quebrar a cadeia de evidencias sobre a origem do dinheiro, e assim dificultar a investigação e o rastreamento do dinheiro ilícito. Para a ocultação, são utilizadas, por exemplo,

13 PONCIANO, Vera Lúcia Feil. Justiça Federal - Organização, competência, administração e funcionamento. Curitiba: Juruá, 2008, p. 158.

${ }^{14}$ MORO, S. F. . Crime de lavagem de dinheiro. 1. ed. São Paulo: Saraiva, 2010, p. 45.

15 BANCO do Brasil. O que é e como ocorre a lavagem de dinheiro e o financiamento do terrorismo. Disponível em: http://www.bb.com.br/portalbb/page251,105,5269,0,0,1,1.bb?codigoNoticia=2970\&codigoMenu=580. Acesso em: 02 nov. 2019.

${ }^{16}$ MORO, S. F. Crime de lavagem de dinheiro. 1. ed. São Paulo: Saraiva, 2010, p. 32.

Rev. Relações Internacionais do Mundo Atual, Curitiba v.2 n.23, p.373-389, Abril-Junho. 2019. 
transferências de dinheiro entre contas correntes, por meio eletrônico; transferência de dinheiro entre empresas, por meio de boletos bancários; operações através de 'conta fantasma' e de 'laranjas", 17.

Ou ainda, etapa em que "o numerário é movimentado por meio de diversas transações de modo a impedir ou dificultar o rastreamento" ${ }^{18}$. Portanto, a partir deste momento, a movimentação do dinheiro não mais possui ligação direta com o praticante do delito que tinha originado os ativos.

E por fim, a terceira e última etapa, integração ou integration:

“consiste na incorporação formal do dinheiro, agora com a aparência de lícito, no sistema econômico, sob a forma de investimentos ou compra de bens, com uma documentação aparentemente legal. A integração é feita, por exemplo, através da realização de investimentos em negócios lícitos, nos diversos setores da economia"19.

Ou seja, nessa última etapa, o resultado da ilicitude "é reintegrado em negócios ou propriedade, com a simulação de investimentos ilícitos" ${ }^{20}$. Nesta etapa, o dinheiro já está bem distante de sua origem, assim, dificilmente existe algum vínculo que permita ligar o criminoso ao dinheiro, que desde agora passa então a ser utilizado na economia formal, através de sociedades simuladas ou, o que é mais comum, por empresas reais, misturando-se na prática empresarial dinheiro obtido regularmente com o dinheiro sujo ocultado nas etapas anteriores da lavagem.

\subsection{O QUE ESTIPULA A LEI DE LAVAGEM DE DINHEIRO N. 12.683/2019}

No delito em comento, o resultado da ilicitude pode ser utilizado no sistema econômico e financeiro como se tivesse sido obtido pelas vias legais. Infelizmente, é praticamente impossível se obter provas contra o autor nesta fase do negócio, que foram praticamente dizimadas pelas fases anteriores.

17 BANCO do Brasil. op. cit.

${ }^{18}$ MORO, S. F. op. cit., p. 32.

19 BANCO do Brasil. O que é e como ocorre a lavagem de dinheiro e o financiamento do terrorismo. Disponível http://www.bb.com.br/portalbb/page251,105,5269,0,0,1,1.bb?codigoNoticia=2970\&codigoMenu=580. Acesso em: 02 nov. 2019.

${ }^{20}$ MORO, S. F. Crime de lavagem de dinheiro. 1. ed. São Paulo: Saraiva, 2010, p. 32.

Rev. Relações Internacionais do Mundo Atual, Curitiba v.2 n.23, p.373-389, Abril-Junho. 2019. 
Com a antiga redação da Lei $\mathrm{n}^{\circ} .9 .613 / 1998$, para que o delito em comento fosse consumado, era necessário que ocorresse, de forma antecedente, a atuação de uma conduta criminosa taxada na legislação brasileira, que era possível ser verificado no artigo $1^{\circ}$, incisos I a IV da referida $l i^{21}$.

Todavia, com o advento da nova Lei Antilavagem - Lei n. 12.683/2012 houve uma supressão do rol dos crimes antecedentes, admitindo-se então, que o delito em comento passasse a ser proveniente de ativos, direitos ou valores decorrentes da prática infracional ${ }^{22}$.

Assim, é possível resumir que a finalidade do delito consiste em transformar dinheiro adquirido de forma ilícita em lícita. Para isso, a lei busca coibir a circulação de dinheiro ilícito - oriundo do narcotráfico e delitos penais adicionais -, não incluindo os valores resultantes de sonegação fiscal, da economia paralela ou invisível, o chamado caixa dois ${ }^{23}$.

Cabe esclarecer que nem sempre a norma penal, por si só, é eficaz e cumpre o seu papel de intimidar os indivíduos com o intuitode prevenir a existência do crime ${ }^{24}$.

Com isso, surgiu o Grupo de Ação Financeira (GAFI/FAFT), um órgão internacional independente, do qual o Brasil é membro, que elabora e edita regras para tutela o sistema financeiro mundial do branqueamento de capitais ${ }^{25}$.

\section{A NOVA LEI DA LAVAGEM DE DINHEIRO E O SIGILO DO ADVOGADO}

Existem alguns casos de atuação ou de participação dolosa do advogado na prática dos delitos em referência em que sua função não está acobertada pelo sigilo, pois, tecnicamente, não constitui atividade jurídica. Nesse contexto, a legislação que disciplina a matéria previu alguns mecanismos de controle denominados compliance, atuando como linha de defesa preventivamente à lavagem de dinheiro.

A reforma em estudo - Lei n. 12.683/2012 inseriu em seu artigo $9^{\circ}$, inciso XIV, como sujeitos obrigados aos mecanismos de controle: "as pessoas físicas ou jurídicas que prestem,

\footnotetext{
${ }^{21}$ BLOK, Marcela. Compliance e governança corportativa. Rio de Janeiro: Freitas Bastos, 2017, p. 122.

${ }^{22}$ VILARDI, Celso Sanchez. A ciência da infração anterior e a utilização do objeto da lavagem. In Boletim IBCCRIM. São Paulo: IBCCRIM, ano 20, n. 237, 2012, p. 17.

${ }^{23}$ BALTAZAR JR., José Paulo. Crimes federais. 10. ed. São Paulo: Saraiva, 2014, p. 1104.

${ }^{24}$ Ibidem, p. 1105.

${ }^{25}$ ORIENTAÇÕES do GAFI. Avaliação nacional dos riscos de branqueamento de capitais e de financiamento do terrorismo. Disponível em: http://www.irn.mj.pt/sections/irn/bc$\mathrm{ft} /$ docs/downloadFile/attachedFile 1 fo/Orientacoes_GAFI.pdf?nocache=1477661551.04. Acesso em: 10 nov. 2019.
}

Rev. Relações Internacionais do Mundo Atual, Curitiba v.2 n.23, p.373-389, Abril-Junho. 2019. 
mesmo que eventualmente, serviços de assessoria, consultoria, contadoria, auditoria, aconselhamento ou assistência de qualquer natureza, em operações [...]"26.

Assim, apesar de a nova Lei Antilavagem não ter inserido expressamente os advogados nessa lista, quando se faz uma análise pormenorizada do dispositivo é possível identificá-los estes entre os profissionais que prestadores de assessoria, consultoria, aconselhamento ou assistência, isto é, artigo $9^{\circ}$, inciso XIV da nova Lei.

\title{
3.1 SOLUÇÕES DE CONFLITO ENTRE O ESTATUTO DA ADVOCACIA E A LEI N. $12.683 / 2012$
}

Havendo a incidência estrita do dispositivo previsto na Lei Antilavagem, em que pode ocorrer que advogados se valham de recursos provenientes do crime ao receber seus honorários, corre-se o risco dos profissionais se desinteressarem pela área criminal (CALLEGARI e WEBER, 2014, p. 119).

A doutrina brasileira e estrangeira decompôs a solução em duas vertentes distintas:

\begin{abstract}
"Deveras, há quem diga que a solução desses casos deve ser estabelecida ao nível do tipo objetivo - a denominada solução objetiva do tipo - local hábil ao manejo de algumas teorias, tais como a adequação social, a redução teleológica do tipo penal, a imputação penal objetiva e as ações neutras, cotianas ou standard. De outro lado, existem autores que sustentam que o problema encontra resposta no elemento subjetivo do tipo penal - a chamada solução do dolo. Finalmente, citem-se aqueles que enxergam, no caso, hipóteses que dão azo à incidência de causas justificantes, como, por exemplo, o estado de necessidade e o exercício regular de direito" 27 (GRANDIS, 2013, p. 170-171) (g.n.)
\end{abstract}

Sendo assim, como tentativa de solucionar os conflitos existentes sobre a problemática envolvida, a doutrina se divide em duas teorias, sendo elas, objetiva ou subjetiva do tipo.

26 BRASIL. Lei $\mathbf{n}^{\mathbf{0}} \mathbf{1 2 . 6 8 3}$, de $\mathbf{9}$ de julho de 2012. Disponível em: http://www.planalto.gov.br/ccivil_03/_Ato2011-2014/2012/Lei/L12683.htm. Acesso em: 14 nov. 2019. $\frac{27}{27}$

Rev. Relações Internacionais do Mundo Atual, Curitiba v.2 n.23, p.373-389, Abril-Junho. 2019. 


\subsubsection{SOLUÇÃO SUBJETIVA DO TIPO}

A solução subjetiva do crime aduz que o elemento anímico do delito em comento seria o dolo, direto ou eventual, na manipulação de ativos e valores. Assim, é o desejo de esconder esses bens, obstruindo a administração da justiça.

Neste viés, invoca-se o dolo de suspensão processual, que dá imunidade de investigação ao advogado, devendo este gozar de tranquilidade e confiança na linha de defesa, dedicando-se a dar cumprimento às prerrogativas do seu mandato na gerência da defesa ${ }^{28}$.

Portanto, em se tratando de advocacia de serviço público e função social, o profissional que a desempenha "é rigorosamente obrigado a manter segredo do que lhe foi confiado na qualidade de advogado ${ }^{29}$ ".

Contudo, caso o profissional contribua na forma dolosa para a incorporação de valores originados de atos ilegais na economia, realizando, concebendo ou planejando operações, mediante a ocultação da sua origem, ou seja, com intenção de realizar o ato tipificado, incorre, consequentemente, na prática do referido delito.

\subsubsection{SOLUÇÃO OBJETIVA DO TIPO}

Em contrapartida, a solução subjetiva do tipo referente ao âmbito objetivo de solução, utilizam como base o objeto jurídico do delito, bem como circunstâncias alheias ao aspecto subjetivo do crime.

Bitencourt entende que o tipo objetivo de um delito se traduz na descrição dos caracteres objetivos que limitam e identificam o teor da proibição penal. Assim sendo, são eles, portanto, o sujeito ativo, a conduta proibida, o objeto da conduta, as formas e meios de ação, etc. Desse modo, quando se fala em tipo objetivo do crime, exclui-se totalmente a consciência do agente (BITENCOURT, 2012, p.134).

A teoria da imputação objetiva ainda esclarece que o delito só existe enquanto ação humana e não como estado, condição social ou modo de ser da pessoa. Assim, Claus Roxin ${ }^{30}$

28 RIOS, Rodrigo Sánchez. Advocacia e lavagem de dinheiro. São Paulo Saraiva, 2010, p. 227.

${ }^{29}$ LEMAIRE, Jean. LesRégles de laprofession d'avocat et lesusagesduBarreau de Paris. 3. Ed., 1976, p. 441.

${ }^{30}$ ROXIM, Claus. Política Criminal e Sistema Jurídico Penal. Rio de Janeiro e São Paulo. Renovar 2000.

Rev. Relações Internacionais do Mundo Atual, Curitiba v.2 n.23, p.373-389, Abril-Junho. 2019. 
entende que não figura, portanto, como princípio geral de imputação objetiva os resultados que não forem previsíveis ou dirigíveis pela vontade, sendo, portanto, atípicos.

Como ensina Eduardo Luiz Santos Cabette ${ }^{31}$, a tese não depende apenas do risco criado, mas do nexo entre risco e resultado:

\footnotetext{
"Não prescinde de nexo causal e nem dos conteúdos finalísticos da ação humana, a imputação objetiva procura solucionar a questão da atribuição da responsabilização criminal por uma conduta a um indivíduo, mediante um critério objetivo referente ao 'risco permitido' e à correlação entre esse risco criado pelo agente e o decorrente resultado".
}

Neste viés, a resolução do impasse da imputação do advogado encontra a ferramenta adequada nessa teoria. Pois assim, o advogado que obtém remuneração maculada desempenhará seu ofício regularmente se não os aplicar em atividade ilícita ou desonesta e não objetivando fraudar a lei, razão pela qual imputa-se risco permitido à sua conduta.

\subsection{O QUE PREVÊ O CÓDIGO PENAL BRASILEIRO}

O Código Penal, em seus artigos 23, inciso III, 24 e 25, prevê expressamente as causas justificantes de legítima defesa, estado de necessidade, exercício regular do direito e estrito cumprimento de dever legal. O efeito de uma causa justificante está na conversão do fato típico em lícito, impedindo a imputação do agente (BITENCOURT, 2013, p. 402).

Sendo assim, uma solução híbrida do problema em evidência, visto que se pauta em elementos subjetivos e objetivos que, juntos, excluem a antijuridicidade, seria o fato de o agente precisa conscientizar-se em agir acobertado por uma excludente, não bastando tão somente que, objetivamente, os pressupostos tenham sido preenchidos ${ }^{32}$.

Damásio de Jesus ensina que, a ausência da junção do elemento objetivo e subjetivo tornam, ao contrário da teoria, a conduta ilícita ${ }^{33}$.

31 CABETTE, Eduardo Luiz Santos. Imputação objetiva e a teoria da adequação social. Disponível em: https://eduardocabette.jusbrasil.com.br/artigos/121938010/imputacao-objetiva-e-teoria-da-adequacao-social. Acesso em: 18 nov. 2019.

32 JESUS, Damásio de. DIREITO PENAL: Parte Geral. 36. Ed. São Paulo: Saraiva, 2015, p. 404.

33 Ibidem, p. 405.

Rev. Relações Internacionais do Mundo Atual, Curitiba v.2 n.23, p.373-389, Abril-Junho. 2019. 


\subsection{LAVAGEM DE DINHEIRO, ADVOCACIA CRIMINAL E O PROJETO DE LEI N.} $442 / 2019$

Recentemente, o Deputado Rubens Bueno (PPS-PR), elaborou o Projeto de Lei $n^{\circ}$. 442/2019 que passaria a configurar como crime, a conduta do advogado que "receba honorários advocatícios, tendo conhecimento ou sendo possível saber a origem ilícita dos recursos com os quais será remunerado" (inciso III do $\S 2^{\circ}$ do art. $1^{\circ}$ da Lei 9613/98). A pena é a mesma de quem ocultou os bens: três a dez anos de reclusão, iniciado em regime fechado, e multa.

O diploma legal em fase de projeto limita-se, tão somente, a punir de forma objetiva, "o recebimento de honorários oriundos da atividade criminosa", pois esse pagamento de honorários advocatícios realizado por um "criminoso" teria a como meta a lavagem de dinheiro, haja visto o desconhecimento de sua origem ${ }^{34}$.

Incumbir tal tarefa aos defensores acaba diferindo das garantias da nossa Constituição Federal quanto à indispensabilidade do advogado à administração da justiça, bem como do Pacto São José da Costa Rica, recepcionado pelo ordenamento brasileiro em 25/09/1992, que garante a livre escolha do advogado, com impossibilidade de condenação sem o que o réu seja julgado com seu procurador constituído ${ }^{35}$.

Conforme assevera o ilustre jurista, Dr. Marcelo Augusto Rodrigues de Lemos $^{36} \mathrm{em}$ seu artigo "O aviltamento do livre exercício da advocacia em tempos de crise":

[...] a ideia de que o advogado deva ser responsável penalmente por receber honorários maculados por ilícito criminal, como pretendem os projetos de lei, é dogmaticamente equivocada. Isso porque não há contemplação do tipo objetivo e, tampouco, dolo direto ou dolo eventual, uma vez que não há incumbência normativa do advogado no sentido de fiscalizar o dinheiro dos seus proventos, especialmente quando há emissão de nota fiscal e recolhimento dos tributos; e pela incidência do princípio da confiança, a entender que o profissional parte da premissa de que todos os indivíduos aderem a um pacto social de cumprimento das normas jurídicas, de modo que não há responsabilidade penal daquele indivíduo que deposita confiança no terceiro que se presta a quebrar tal avença.

\footnotetext{
${ }^{34}$ MAIA, Roberto Serra da Silva. Lavagem de dinheiro e advocacia criminal: breves considerações acerca do Projeto de Lei n. 442/2019. Disponível em: https://jus.com.br/artigos/72481/lavagem-de-dinheiro-e-advocaciacriminal-breves-consideracoes-acerca-do-projeto-de-lei-n-442-2019. Acesso em: 24 nov. 2019.

35 CALLEGARI, André; WEBER, Ariel B. .Lavagem de Dinheiro. 2. ed. São Paulo: Atlas, 2017, p. 214.

${ }^{36}$ LEMOS, Marcelo Augusto Rodrigues de. $\mathrm{O}$ aviltamento do livre exercício da advocacia em tempos de crise. Disponível em: https://www.conjur.com.br/2019-set-01/marcelo-lemos-aviltamento-advocacia-temposcrise\#_ftn15. Acesso em: 26 junho 2020.
}

Rev. Relações Internacionais do Mundo Atual, Curitiba v.2 n.23, p.373-389, Abril-Junho. 2019. 
Assim, pode-se concluir, portanto, que seria atípica a conduta do advogado que obtém remuneração proveniente de infrações penais, desde que este, não atue de má-fé.

\section{CONSIDERAÇÕES FINAIS}

Ao tratar do recebimento de remuneração maculada, a doutrina apresenta diversos posicionamento significativos para a imputação de responsabilidade criminal ao advogado pela obtenção de remuneração maculada.

Além disso, apesar de a tese de limitação do elemento subjetivo ter bastante receptividade na doutrina brasileira, alguns outros doutrinadores entendem que a melhor tese se encontra no elemento objetivo.

A proteção dos interesses sociais no Direito pátrio guia, em nossa doutrina, a defesa das prerrogativas do profissional é consequência do resguardo mais primordial das garantias individuais previstas no texto constitucional.

O disposto na lei em comento assegura a eventualidade de rastreamento do capital para que as autoridades públicas possam conhecer o caminho entre a infração e o destino dos bens, esclarecendo-se que não se pressiona o advogado ao dever de verificar a fonte do dinheiro ou os atos que justificaram sua aquisição.

Nesse diapasão, resta evidente, portanto, que o profissional jurídico não está imune à legislação em comento e, ainda, o fato do ato ser praticado no interior de seu estaelecimento não o protege da incidência da norma penal.

Dessa forma, portanto, seria atípica a conduta do advogado que obtém remuneração proveniente de infrações penais, desde que, claramente, não atue de má-fé. De maneira que, pensar o contrário, por consequência, poderia implicar restrição de garantias fundamentais.

\section{REFERÊNCIAS}

BALTAZAR JR., José Paulo. Crimes federais. 10. ed. São Paulo: Saraiva, 2014.

BANCO do Brasil. O que é e como ocorre a lavagem de dinheiro e o financiamento ao terrorismo. enu=580. Acesso em: 13 nov. 2019.

Rev. Relações Internacionais do Mundo Atual, Curitiba v.2 n.23, p.373-389, Abril-Junho. 2019. 
BARBACETTO, Gianni; TRAVAGLIO, Peter Gomez Marco. Operação Mãos Limpas - A verdade sobre a operação italiano que inspirou a Lava Jato. Porto Alegre: CDG, 2016.

BARROS, Marco Antônio de. Lavagem de Capitais e Obrigações Civis Correlatas: com comentários, artigo por artigo, à Lei 9.613/1998. 4. Ed. São Paulo: Editora Revista dos Tribunais, 2013.

BLOK, Marcela. Compliance e governança corportativa. Rio de Janeiro: Freitas Bastos, 2017.

BRASIL. Lei $\mathbf{n}^{\circ}$ 12.683, de 9 de julho de 2012. Disponível em: http://www.planalto.gov.br/ccivil_03/_Ato2011-2014/2012/Lei/L12683.htm. Acesso em: 10 nov. 2019.

CABETTE, Eduardo Luiz Santos. Imputação objetiva e a teoria da adequação social. Disponível em: https://eduardocabette.jusbrasil.com.br/artigos/121938010/imputacaoobjetiva-e-teoria-da-adequacao-social. Acesso em: 18 nov. 2019.

CALLEGARI, André; WEBER, Ariel B. .Lavagem de Dinheiro. 2. ed. São Paulo: Atlas, 2017.

CERVINI, Raúl; TERRA DE OLIVEIRA, William; GOMES, Luiz Flávio. Lei de Lavagem de Capitais. São Paulo: Revista dos Tribunais, 1998.

JESUS, Damásio de. DIREITO PENAL: Parte Geral. 36. Ed. São Paulo: Saraiva, 2015.

LEMAIRE, Jean. LesRégles de laprofession d'avocat et lesusagesduBarreau de Paris. 3. Ed., 1976.

LEMOS, Marcelo Augusto Rodrigues de. O aviltamento do livre exercício da advocacia em tempos de crise. Disponível em: https://www.conjur.com.br/2019-set-01/marcelo-lemosaviltamento-advocacia-tempos-crise\#_ftn15. Acesso em: 26 junho 2020.

LIMA, Vinicius Melo de. Lavagem de dinheiro \& ações neutras: critérios de imputação penal legítima. 1. ed. Curitiba: Juruá Editora, 2014.

MAIA, Roberto Serra da Silva. Lavagem de dinheiro e advocacia criminal: breves considerações acerca do Projeto de Lei n. 442/2019. Disponível em: https://jus.com.br/artigos/72481/lavagem-de-dinheiro-e-advocacia-criminal-brevesconsideracoes-acerca-do-projeto-de-lei-n-442-2019. Acesso em: 24 nov. 2019.

MORO, S. F. . Crime de lavagem de dinheiro. 1. ed. São Paulo: Saraiva, 2010.

ORIENTAÇÕES do GAFI. Avaliação nacional dos riscos de branqueamento de capitais e de financiamento do terrorismo. Disponível em: http://www.irn.mj.pt/sections/irn/bc$\mathrm{ft} /$ docs/downloadFile/attachedFile_1_f0/Orientacoes_GAFI.pdf?nocache $=1477661551.04$.

Acesso em: 10 nov. 2019.

PINTO, Edson. Lavagem de Capitais e Paraísos Fiscais. São Paulo: Atlas, 2007.

PONCIANO, Vera Lúcia Feil. Justiça Federal - Organização, competência, administração e funcionamento. Curitiba: Juruá, 2008.

Rev. Relações Internacionais do Mundo Atual, Curitiba v.2 n.23, p.373-389, Abril-Junho. 2019. 
PRADO, Luiz Regis. Curso de Direito Penal Brasileiro. 11. ed., São Paulo: Revista dos Tribunais, 2012.

RIOS, Rodrigo Sánchez. Advocacia e lavagem de dinheiro. São Paulo Saraiva, 2010.

ROSA, Rodrigo Silveira. Delito de omissão - Sonegação fiscal não consiste em infração antecedente da lavagem. Disponível em: http://www.conjur.com.br/2014-nov-30/sonegacaofiscal-nao-consiste-infracao-antecedente-lavagem. Acesso em: 21 nov. 2019.

ROXIM, Claus. Política Criminal e Sistema Jurídico Penal. Rio de Janeiro e São Paulo. Renovar 2000.

VILARDI, Celso Sanchez. A ciência da infração anterior e a utilização do objeto da lavagem. In Boletim IBCCRIM. São Paulo: IBCCRIM, ano 20, n. 237, 2012. 


\section{ANEXO I}

\section{NOTA DE ESCLARECIMENTO}

O artigo ora composto de 16 páginas, com 22 referências bibliográficas, e foi por mim redigido como atividade integrante da avaliação da disciplina ministrada pelo Dr. Sérgio Moro. A redação do artigo foi minha e, infelizmente, acabou acontecendo a falha metodológica consistente na ausência de citação do ilustre Autor Dr. Marcelo Augusto Rodrigues de Lemos. Reconheço a falha não intencional, mesmo porque não havia motivos para não citar o autor, tendo em vista que o trabalho citou mais de vinte outros autores. O artigo foi por mim redigido, bem como pedi escusas ao Autor do trabalho, as quais foram aceitas. O Centro Universitário Curitiba - Unicuritiba já retirou o artigo da revista "Relações Internacionais no Mundo Atual". Aproveito o ensejo para pedir sinceras desculpas ao Professor Sérgio Moro, bem corno à instituição de ensino.

27 de junho de 2020

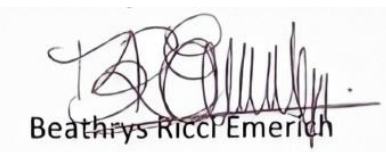

Rev. Relações Internacionais do Mundo Atual, Curitiba v.2 n.23, p.373-389, Abril-Junho. 2019. 